\title{
SCREEN TIME AND ITS EFFECT ON \\ DIETARY HABITS AND LIFESTYLE AMONG SCHOOLCHILDREN
}

\author{
Konstantinos D. Tambalis ${ }^{1}$, Demosthenes B. Panagiotakos ${ }^{1}$, Glykeria Psarra ${ }^{1}$, Labros S. Sidossis ${ }^{1,2}$ \\ ${ }^{1}$ Department of Nutrition and Dietetics, Harokopio University, Athens, Greece \\ 2Department of Kinesiology and Health, Rutgers University, New Brunswick, New Jersey, USA
}

\section{SUMMARY}

Objective: The aim of the study was to determine the associations between recreational screen time and dietary habits and lifestyle factors in a representative sample of schoolchildren.

Methods: Observational, cross-sectional study data were derived from 177,091 children aged 8 to 17 years participating in a health survey. Recreational screen time, physical activity (PA), and sleeping hours were assessed through self-completed questionnaires. Dietary habits were evaluated via the Mediterranean Diet Quality Index for children and adolescents (KIDMED) test. Anthropometric and physical fitness (PF) estimations were obtained by trained investigators.

Results: Binary logistic regression comparisons between screen time levels (e.g. $<2 \mathrm{vs.} \geq 2-<3 \mathrm{~h} / \mathrm{d},<2 \mathrm{vs} . \geq 3-<4 \mathrm{~h} / \mathrm{d}$ and $<2 \mathrm{vs} . \geq 4 \mathrm{~h} / \mathrm{d}$ ) and dietary habits showed that the longer the screen time the increased the odds of unhealthy dietary habits such as skipping breakfast, consuming fast food frequently, and eating sweets frequently, and the decreased the odds of healthy dietary habits such as consuming a second fruit every day, consuming fresh or cooked vegetables orland fish regularly, in both genders, after adjusting for several covariates. Furthermore, the longer the screen time the increased the odds of total and central obesity, insufficient sleep $(<8-9 \mathrm{~h} / \mathrm{d})$, and inadequate PA, and the decreased the odds of healthy PF.

Conclusions: The longer the screen time the unhealthier dietary habits and lifestyle profile among schoolchildren, after adjusting for several covariates.

Key words: children, adolescents, Mediterranean diet, screen time

Address for correspondence: Labros S. Sidossis, Department of Kinesiology and Health, Rutgers University, 70 Lipman Drive, New Brunswick, NJ 08901-8525, USA. E-mail: Isidossis@kines.rutgers.edu

https://doi.org/10.21101/cejph.a6097

\section{INTRODUCTION}

In the last decades, the availability of an increasing variety of electronic media devices throughout the world has given prominence to recreational screen time as a more complicated issue. Although television (TV) viewing constitutes the most common type of screen-based activities among schoolchildren, video games, computer (PC) use, and ownership of devices such as tablets and smart phones have become part of everyday life at an ever younger age. Nevertheless, there is a growing interest in the influence of screen time on children and adolescent's health (1). Screen time in children and adolescents is associated with adverse health and physiological consequences, including decreased physical fitness (PF) and poor psychosocial and physical health (2). Recent guidance from the Royal College of Paediatrics and Child Health highlights that the apparent adverse health effects of screen time could be attributed, at least in part, to the absence of other health activities, such as exercise, good sleep, and socialization (3). Moreover, there is a plethora of scientific evidence that screen time is associated with childhood obesity, which is partially attributed to increasing in energy consumption and the lack of time available for physical activity (PA) (4). Specifically, it is considered that the number of hours spent in front of the screen is directly connected to the consumption of unhealthy foods during the day (5). Taken into consideration these concerns, several expert groups have proposed controlling screen time for schoolchildren and younger children. The major recommendation within all guidelines is to limit recreational screen time (e.g., TV, electronic games, computers, and mobile phones) to no more than 2 hours daily $(6,7)$. Childhood and adolescence are crucial lifetime periods that mostly coincide with unhealthy lifestyle patterns that are likely to track into adulthood (8).

Association of obesity (9-11), sleeping $(9,10)$, and PF (12-14) with screen time has been investigated among schoolchildren. Moreover, screen time is constantly associated with features as unhealthy dietary habits (15-17). However, most studies have explored the association of each factor independently and in specific age groups. Also, there are no representative national studies among schoolchildren that analyzed the effects of longer screen time consumption on lifestyle factors.

Consequently, this paper aimed to determine associations between the length of screen time and dietary habits and lifestyle profile in a representative sample of Greek schoolchildren aged 8-17 years, taken into consideration several covariates. It was 
hypothesized that longer self-reported screen time would be strongly associated with the consumption of an unhealthy diet. It was also hypothesized that the longer screen time would be associated with an unhealthier lifestyle profile including obesity, low PF, insufficient sleeping, and inadequate PA levels.

\section{MATERIALS AND METHODS}

\section{Participants}

Representative data were collected through a populationbased, school health survey between March 2015 and May 2015. Trained investigators incorporated anthropometric, PF, nutrition, sedentary habits, and PA data. In total, parents of 177,091 (51\% of boys) schoolchildren aged 8 to 17 years gave their consent to participate in the study.

\section{Assessment of Demographic and Anthropometric Measurements}

The demographic information of students was provided by the school headmaster. Anthropometric measurements (height, body weight, and waist circumference) were performed in the morning using a standardized process by physical education (PE) instructors. Body mass index (BMI) status (normal weight, overweight, obese) was classified using the International Obesity Task Force age- and gender-specific BMI cut-off criteria (18). Central obesity was defined as waist circumference $(\mathrm{cm})$ to height $(\mathrm{cm})$ ratio $(\mathrm{WHtR}) \geq 0.5$ (19).

\section{Assessment of Physical Fitness Levels}

The EUROFIT test battery was used to assess children's PF measurements (20). The battery consists of 5 tests: a multi-stage $20 \mathrm{~m}$ shuttle run test ( $20 \mathrm{~m} \mathrm{SRT}$ ) to estimate aerobic performance; a maximum $10 \times 5 \mathrm{~m}$ shuttle run test $(10 \times 5 \mathrm{~m} \mathrm{SRT})$ to evaluate speed and agility; a sit-ups test in $30 \mathrm{~s}$ (SUs) to evaluate the endurance of the abdominal and hip-flexor muscles; a standing long jump (SLJ) to estimate lower body explosive power; and a sit and reach (SR) test to measure flexibility. Moreover, schoolchildren were classified into low and healthy cardiorespiratory fitness (CRF) levels (21).

\section{Assessment of Screen Time}

Participating children's screen, dietary and PA habits were recorded using an electronic questionnaire. Daily time spent in recreational screen-based activities (TV viewing, use of the Internet for non-study reasons, playing with PC or/and console games or/and mobile phone) was calculated for each schoolchild. Specifically, the schoolchildren were asked how many hours of the recreational screen time they spent on a typical school day and a typical weekend day, based on questions adapted from the US Youth Risk Behavior Surveillance System (22). The response options included no screen watching, $0.5 \mathrm{~h}, 1 \mathrm{~h}, 1.5 \mathrm{~h}, 2 \mathrm{~h}, 2.5$ $\mathrm{h}, 3 \mathrm{~h}, 4 \mathrm{~h}$, and $\geq 5 \mathrm{~h}$ of the screen watching per day. A weighted mean number of hours of screen watching per day were calculated as follows: [(time of screen on weekdays $\times 5)+($ time of screen on weekend days $\times 2)] / 7$. Moreover, students were classified as exceeding ( $>2 \mathrm{~h}$ per day) or not ( $\leq 2 \mathrm{~h}$ per day) the recommended daily time spent in screen activities $(2-4)$.

\section{Assessment of Self-reported Physical Activity and Sleeping Time}

About PA habits, self-reported patterns of PA were incorporated. The questionnaire applied has been previously employed for children in epidemiological studies, and included simple closed-type questions regarding children's frequency, time, and intensity of participation in PA. Those children who engaged in MVPA as a minimum for 60 minutes daily were considered as fulfilling the recommendations for PA (23).

Moreover, we classified as meeting the recommendations of sufficient sleep those children who were sleeping at least 9 hours daily and those adolescents who were sleeping at least 8 hours per day. Children and adolescents that were sleeping daily fewer than the number of recommended hours were classified as having insufficient sleep (24).

\section{Assessment of Dietary Habits}

Dietary habits were assessed using the Mediterranean Diet Quality Index for children and adolescents (KIDMED) (25). The KIDMED score varies within limits of 0 to 12 and is sorted into 3 levels: $\geq 8$ suggesting an optimal adherence to the Mediterranean diet (MD) (sufficient dietary habits); 4-7 suggesting a common adherence to the MD and enhancement is desirable to adjust dietary intake to guidelines (relatively sufficient dietary habits); and $\leq 3$ suggesting a low adherence to the MD and generally a low diet quality (insufficient dietary habits).

\section{Ethical Approval}

This study was conducted according to the guidelines laid down in the Declaration of Helsinki and all procedures involving research study participants were approved by the Ethical Review Board of the Ministry of Education and Religious Affairs and the Ethical Committee of Harokopio University.

\section{Data Analysis}

Continuous variables are expressed as mean and standard deviation (SD). The $\chi^{2}$ test evaluated relationships between the categorical variables and the Student's t-test were applied to evaluate differences in mean values of normally distributed variables. To assess the potential effect of several dietary habits on the screen time categories ( $<2 \mathrm{vs} . \geq 2-<3 \mathrm{~h} / \mathrm{d},<2 \mathrm{vs} . \geq 3-<4 \mathrm{~h} / \mathrm{d}$, and $<2 \mathrm{vs}$. $\geq 4 \mathrm{~h} / \mathrm{d}$ ), binary logistic regression analysis was implemented and odds ratio (OR) with the corresponding 95\% confidence interval (CI) were calculated, adjusted for confounders. Moreover, to evaluate the possible effect of several demographic and lifestyle factors on the screen time categories, stepwise binary logistic regression analysis was implemented and odds ratios (OR) with $95 \%$ confidence intervals $(\mathrm{CI})$ were determined. Hosmer-Lemeshow goodness-of-fit test was calculated to assess the model's goodness-of-fit. Moreover, the residual analysis was applied with the use of the dbeta, the leverage, and Cook's distance D statistics 
to recognize outliers and influential observations. SPSS version 23.0 software for Windows (SPSS Inc., Chicago, II, USA) was used for all statistical analyses. The statistical significance level was set at an alpha value of $<0.05$.

\section{RESULTS}

A total of 177,091 schoolchildren aged 8 to 17 years were involved in the study. Schoolchildren's descriptive characteristics, by gender, are shown in Table 1. A total of 114,673 (65.4\%) schoolchildren spent $<2 \mathrm{~h}$ of screen time per day and 61,427 (34.6\%) schoolchildren spent $\geq 2 \mathrm{~h}$ of screen time per day. The mean screen time was $1.6 \mathrm{~h} / \mathrm{d}(\mathrm{SD}=1.5)$ and $1.3 \mathrm{~h} / \mathrm{d}(\mathrm{SD}=1.2)$ for boys and girls, respectively $(\mathrm{p}<0.001)$.

Table 2 provides characteristics of the participants by the length of exposure to screens and gender. Schoolchildren of both genders who classified with acceptable $(<2 \mathrm{~h} / \mathrm{d})$ screen time were younger, had better dietary habits, anthropometric profile, and increased $\mathrm{PF}$ and sleeping time as compared to each one of categories with increased screen time (all p-values $<0.05$ ).

Nevertheless, given that schoolchildren with acceptable screen time presented a better dietary profile in comparison to all other participants, further data analysis was applied to estimate the effect of screen time categories on specific dietary habits (Table 3). Specifically, binary logistic regression analysis showed that skipping breakfast, consuming fast food frequently, eating pasta or rice almost every day, and eating sweets frequently were associated with increased screen time. In details, comparisons between screen time levels showed that the longer the screen time the increased the odds of unhealthy dietary habits in both genders, after adjusting for several covariates. Conversely, the results showed that that the longer the screen time the decreased the odds of healthy dietary habits such as consuming a second fruit every day, consuming fresh or cooked vegetables or/and fish regularly, eating pulses, eating nuts, and consuming two yogurts and/or some cheese daily, in both genders (Table 3).

Finally, Table 4 presents stepwise binary logistic regression analyses (3 models) to calculate the effects of screen time levels on several lifestyle factors in both genders, separately. The analysis showed that age was positively associated with increased screen time. Furthermore, our data revealed that the longer the screen time the increased the odds of total and central obesity, insufficient sleep, and inadequate PA, in both genders. Moreover, the results showed that the longer the screen time the decreased the odds of healthy $\mathrm{CRF}$ and relatively/sufficient dietary habits, in boys and girls.

\section{DISCUSSION}

To our best of knowledge, this study provides significant evidence of the role of length of time in the link between screen viewing and age, dietary habits, sleeping, childhood obesity, $\mathrm{PF}$, and $\mathrm{PA}$, taken into consideration representative data from

Table 1. Descriptive characteristics of participants aged 8-17 years, by gender

\begin{tabular}{|c|c|c|c|c|}
\hline & $\begin{array}{c}\text { Total } \\
(\mathrm{n}=177,091) \\
\text { mean }(\mathrm{SD})\end{array}$ & $\begin{array}{c}\text { Boys } \\
(n=90,821) \\
\text { mean }(S D)\end{array}$ & $\begin{array}{c}\text { Girls } \\
(n=86,270) \\
\text { mean }(S D)\end{array}$ & $p$-value* \\
\hline Age (years) & $9.88(2.8)$ & $9.91(2.8)$ & $9.84(2.8)$ & $<0.001$ \\
\hline Children 8-11 years, n (\%) & $100,134(100)$ & $51,161(50.9)$ & $48,973(49.1)$ & $<0.001$ \\
\hline Adolescents $12-17$ years, $n(\%)$ & $76,975(100)$ & $39,660(52.5)$ & $37,315(47.5)$ & $<0.001$ \\
\hline Height $(\mathrm{cm})$ & $149(13.5)$ & $150(14.5)$ & $148(12.3)$ & $<0.001$ \\
\hline Weight (kg) & $44.5(14.2)$ & $45.5(15.2)$ & $43.5(12.9)$ & $<0.001$ \\
\hline BMI $\left(\mathrm{kg} / \mathrm{m}^{2}\right)$ & $19.7(3.8)$ & $19.8(3.8)$ & $19.5(3.7)$ & $<0.001$ \\
\hline Waist circumference $(\mathrm{cm})$ & $70.4(10.7)$ & $71.6(11.1)$ & $69.2(10.2)$ & $<0.001$ \\
\hline Waist to height ratio & $0.30(0.46)$ & $0.32(0.47)$ & $0.28(0.45)$ & $<0.001$ \\
\hline Screen time $\leq 2 \mathrm{~h} / \mathrm{d}, \mathrm{n}(\%)$ & $114,673(65.4)$ & $55,149(62.1)$ & $59,279(68.7)$ & $<0.001$ \\
\hline Screen time >2-<3 h/d, n (\%) & $37,446(21.1)$ & $20,707(22.8)$ & $16,739(19.4)$ & $<0.001$ \\
\hline Screen time $>3-<4$ h/d, $n(\%)$ & $12,234(6.9)$ & $6,539(7.2)$ & $5,695(6.6)$ & $<0.001$ \\
\hline Screen time $\geq 4$ h/d, n (\%) & $11,747(6.6)$ & $7,174(7.9)$ & $4,573(5.3)$ & $<0.001$ \\
\hline KIDMED score $(0-12)^{\dagger}$ & $6.7(2.4)$ & $6.7(2.4)$ & $6.8(2.4)$ & $<0.001$ \\
\hline Physical activity (h/wk) & $9.4(5.5)$ & $10.4(5.9)$ & $8.4(5.2)$ & $<0.001$ \\
\hline Sleeping time, $(\mathrm{h} / \mathrm{d})$ & $8.6(1.6)$ & $8.6(1.6)$ & $8.7(1.6)$ & $<0.001$ \\
\hline $20 \mathrm{~m}$ shuttle run (stages) & $3.5(2.1)$ & $4.0(2.3)$ & $2.8(1.5)$ & $<0.001$ \\
\hline Standing long jump (cm) & $117(55.7)$ & $124(59.3)$ & $110(50.5)$ & $<0.001$ \\
\hline Sit and reach $(\mathrm{cm})$ & $15.4(8.3)$ & $13.2(7.6)$ & $17.7(8.3)$ & $<0.001$ \\
\hline Sit-ups in 30 seconds (n) & $19.7(5.7)$ & $20.6(5.8)$ & $18.7(5.3)$ & $<0.001$ \\
\hline $10 \times 5$-meter shuttle run (sec) & $21.5(3.4)$ & $21.0(3.4)$ & $22.1(3.3)$ & $<0.001$ \\
\hline
\end{tabular}

KIDMED - Mediterranean Diet Quality Index for children and adolescents; †KIDMED score ( $\leq 3$ : insufficient dietary habits, 4-7: relatively sufficient dietary habits, $\geq 8$ : sufficient dietary habits); ${ }^{*} p$-values for differences between boys and girls 
Table 2. Demographic, anthropometric and behavioural characteristics by level of screen time in participants aged 8-17 years, by gender

\begin{tabular}{|c|c|c|c|c|}
\hline & \multicolumn{4}{|c|}{ Screen time $(\mathrm{h} / \mathrm{d})$} \\
\hline & $\begin{array}{c}<2 \mathrm{~h} / \mathrm{d} \\
\text { mean }(\mathrm{SD})\end{array}$ & $\begin{array}{l}\geq 2-<3 \mathrm{~h} / \mathrm{d} \\
\text { mean }(S D)\end{array}$ & $\begin{array}{l}\geq 3-<4 \mathrm{~h} / \mathrm{d} \\
\text { mean }(\mathrm{SD})\end{array}$ & $\begin{array}{c}\geq 4 \mathrm{~h} / \mathrm{d} \\
\text { mean (SD) }\end{array}$ \\
\hline \multicolumn{5}{|l|}{ Boys } \\
\hline Number & 55,649 & 21,007 & 6,739 & 7,426 \\
\hline Age (years) & $11.1(2.1)$ & $11.7(2.3)^{*}$ & $11.9(2.4)^{*}$ & $12.1(2.6)^{*}$ \\
\hline Body mass index $\left(\mathrm{kg} / \mathrm{m}^{2}\right)$ & $19.5(3.7)$ & $20.0(3.9)^{*}$ & $20.3(4.1)^{*}$ & $20.5(4.2)^{*}$ \\
\hline Waist (cm) & $70.8(10.7)$ & $72.5(11.2)^{*}$ & $73.5(11.7)^{*}$ & $74.1(12.2)^{*}$ \\
\hline KIDMED score (0-12) & $7.1(2.3)$ & $6.3(2.3)^{*}$ & $5.9(2.4)^{*}$ & $5.4(2.6)^{*}$ \\
\hline Physical activity (hours/week) & $10.7(5.7)$ & $10.1(5.7)^{\star}$ & $10.0(6.1)^{*}$ & $10.1(5.8)^{*}$ \\
\hline Sleeping time (hours/day) & $8.7(1.7)$ & $8.5(1.5)^{\star}$ & $8.4(1.5)^{\star}$ & $8.2(1.9)^{\star}$ \\
\hline 20 m shuttle run (laps) & $36.7(20.4)$ & $35.2(21.1)^{\star}$ & $35.1(21.3)^{\star}$ & $34.6(21.1)^{*}$ \\
\hline Standing long jump (cm) & $126(60.5)$ & $123(58.2)^{*}$ & $123(59.1)^{*}$ & $121(62.0)^{*}$ \\
\hline Sit-Ups in 30 seconds (n) & $20.7(5.9)$ & $20.5(5.8)^{*}$ & $20.4(5.9)^{*}$ & $20.4(6.3)^{*}$ \\
\hline $10 \times 5$-meter shuttle run (sec) & $20.9(3.6)$ & $21.0(3.2)$ & $21.0(3.4)$ & $21.2(3.7)^{*}$ \\
\hline Sit and reach $(\mathrm{cm})$ & $13.3(7.5)$ & $13.0(7.7)^{\star}$ & $12.9(7.9)^{*}$ & $12.7(7.9)^{*}$ \\
\hline \multicolumn{5}{|l|}{ Girls } \\
\hline Number & 59,279 & 16,723 & 5,695 & 4,573 \\
\hline Age (years) & $11.0(2.0)$ & $11.8(2.3)^{*}$ & $12.1(2.4)^{*}$ & $12.4(2.6)^{*}$ \\
\hline Body mass index $\left(\mathrm{kg} / \mathrm{m}^{2}\right)$ & $19.3(3.6)$ & $19.9(3.8)^{*}$ & $20.1(3.9)^{*}$ & $20.5(4.1)^{*}$ \\
\hline Waist (cm) & $68.6(10.0)$ & $70.4(10.4)^{*}$ & $71.2(10.4)^{*}$ & $72.1(10.8)^{*}$ \\
\hline KIDMED score (0-12) & $7.1(2.3)$ & $6.2(2.3)^{*}$ & $5.8(2.4)^{*}$ & $5.2(2.5)^{*}$ \\
\hline Physical activity (hours/week) & $8.6(5.2)$ & $8.2(5.1)^{*}$ & $8.3(5.1)^{*}$ & $8.3(5.2)^{*}$ \\
\hline Sleeping time (hours/day) & $8.7(1.6)$ & $8.5(1.4)^{*}$ & $8.3(1.4)^{*}$ & $8.1(1.7)^{\star}$ \\
\hline 20m shuttle run (laps) & $25.7(14.0)$ & $25.0(13.7)^{*}$ & $24.6(13.5)^{*}$ & $24.1(13.4)^{*}$ \\
\hline Standing long jump (cm) & $110(49.8)$ & $109(52.0)$ & $108(52.8)^{*}$ & $108(52.5)^{*}$ \\
\hline Sit-ups in 30 seconds (n) & $18.8(5.3)$ & $18.7(5.3)^{*}$ & $18.5(5.2)^{*}$ & $18.2(5.2)^{*}$ \\
\hline $10 \times 5$-meter shuttle run (sec) & $22.0(3.3)$ & $22.1(3.3)$ & $22.2(3.5)$ & $22.2(3.2)$ \\
\hline Sit and reach $(\mathrm{cm})$ & $17.8(8.2)$ & $17.7(8.4)$ & $17.7(8.6)$ & $17.5(8.7)^{*}$ \\
\hline
\end{tabular}

${ }^{*} \mathrm{p}$-values $<0.05$ for comparisons between $<2 \mathrm{~h} / \mathrm{d}$ group and $\geq 2-<3 \mathrm{~h} / \mathrm{d}, \geq 3-<4 \mathrm{~h} / \mathrm{d}$, and $\geq 4 \mathrm{~h} / \mathrm{d}$ group, respectively; KIDMED - Mediterranean Diet Quality Index for children and adolescents

171,091 boys and girls (aged 8-17 years). The most important findings of this study indicate that participants from both genders who classified with acceptable screen time were younger, had better dietary habits, anthropometric profile, and increased PF and sleeping time; the longer the screen time the increased the odds of unhealthy dietary habits; and the longer the screen time the unhealthier the lifestyle profile, in both genders. These associations were independent of numerous covariates, including obesity and PA levels.

Our results showed that almost $65 \%$ of schoolchildren incorporated $<2 \mathrm{~h}$ of screen time per day and $35 \%$ of them incorporated $\geq 2 \mathrm{~h}$ of screen time per day, while the mean screen time was 1.6 $\mathrm{h} / \mathrm{d}$ and $1.3 \mathrm{~h} / \mathrm{d}$, for boys and girls, respectively. The above findings are similar to a review study that reported on average 1.8-2.8 $\mathrm{h}$ of screen time per day among youth, while a great proportion of them $(66 \%)$ were "low users" ( $<2 \mathrm{~h}$ /day) (4). In contrast, another review study suggested that in the US, schoolchildren spend almost 7 hours per day in front of a screen (26), while it is considered that $62-83 \%$ of adolescents from westernized countries are surpassing the recommendations of no more than $2 \mathrm{~h}$ of screen time per day (27). Amongst the potential reasons why screens have been commonly used are the limited options for leisure in urban centres and the parents' concern regarding their children's safety due to increasing violence in cities $(4,28)$. That practice replaced outdoor physical activities as sources of leisure and entertainment for schoolchildren.

We found that the longer screen time was associated with increased odds of unhealthy dietary habits and decreased odds of healthy dietary habits. Similar study results among Canadian children aged 9 to 11 years suggested that screen time was negatively associated with the frequency of consumption of vegetables and fruits, and positively associated with the frequency of consumption of sweets, pastries, and fast food, independent of covariates (29). In line with us, a review among children concluded that there is a significant association between screen time and unhealthy dietary habits such as fewer fruits and vegetable consumption, and greater consumption of energy-dense snacks and sugar (15). Also, a systematic review of reviews revealed that there is an associa- 
Table 3. Results of logistic regression models - association of 8-17 years old participant's dietary habits with screen time levels

\begin{tabular}{|c|c|c|c|}
\hline Predictors & $\begin{array}{c}\text { Model } 1 \\
<2 \text { vs. } \geq 2-<3 \mathrm{~h} / \mathrm{d} \\
\text { OR }(95 \% \mathrm{Cl})\end{array}$ & $\begin{array}{c}\text { Model } 2 \\
<2 \text { vs. } \geq 3-<4 \text { h/d } \\
\text { OR }(95 \% \mathrm{Cl})\end{array}$ & $\begin{array}{c}\text { Model } 3 \\
<2 \text { vs. } \geq 4 \mathrm{~h} / \mathrm{d} \\
\text { OR }(95 \% \mathrm{Cl})\end{array}$ \\
\hline \multicolumn{4}{|l|}{ Boys } \\
\hline Skips breakfast (no vs. yes) & $1.17(1.12-1.21)$ & $1.35(1.26-1.44)$ & $1.86(1.76-1.96)$ \\
\hline Consumes fast food more than once weekly (no vs. yes) & $1.76(1.70-1.83)$ & $2.43(2.29-2.58)$ & $3.38(3.20-3.56)$ \\
\hline Takes sweets and candy several times every day (no vs. yes) & $2.00(1.92-2.08)$ & $2.64(2.48-2.80)$ & $4.12(3.90-4.35)$ \\
\hline Eats pasta or rice almost every day (no vs. yes) & $1.01(0.98-1.05)$ & $1.07(1.01-1.13)$ & $1.22(1.16-1.29)$ \\
\hline Has a second fruit every day (no vs. yes) & $0.65(0.63-0.67)$ & $0.61(0.58-0.65)$ & $0.60(0.57-0.64)$ \\
\hline Has fresh or cooked vegetables more than once a day (no vs. yes) & $0.88(0.84-0.91)$ & $0.83(0.77-0.89)$ & $0.83(0.77-0.89)$ \\
\hline Consumes fish regularly (at least 2-3/week) (no vs. yes) & $0.65(0.63-0.67)$ & $0.61(0.58-0.65)$ & $0.58(0.55-0.61)$ \\
\hline Eats pulses >1/week (no vs. yes) & $0.80(0.77-0.83)$ & $0.70(0.66-0.75)$ & $0.57(0.54-0.60)$ \\
\hline Consumes nuts regularly (at least 2-3/week) (no vs. yes) & $0.85(0.83-0.88)$ & $0.82(0.77-0.86)$ & $0.79(0.75-0.84)$ \\
\hline Takes two yoghurts and/or some cheese ( $40 \mathrm{~g}$ ) daily (no vs. yes) & $0.98(0.94-1.02)$ & $0.88(0.82-0.95)$ & $0.79(0.75-0.85)$ \\
\hline \multicolumn{4}{|l|}{ Girls } \\
\hline Skips breakfast (no vs. yes) & $1.34(1.28-1.39)$ & $1.63(1.52-1.75)$ & $2.06(1.92-2.19)$ \\
\hline Consumes fast food more than once weekly (no vs. yes) & $1.85(1.76-1.93)$ & $2.42(2.25-2.41)$ & $3.98(3.72-4.25)$ \\
\hline Takes sweets and candy several times every day (no vs. yes) & $2.25(2.16-2.35)$ & $3.01(2.86-3.30)$ & $4.74(4.43-5.06)$ \\
\hline Eats pasta or rice almost every day (no vs. yes) & $1.00(0.96-1.04)$ & $1.07(1.01-1.15)$ & $1.37(1.29-1.46)$ \\
\hline Has a second fruit every day (no vs. yes) & $0.60(0.58-0.62)$ & $0.55(0.52-0.59)$ & $0.51(0.48-0.55)$ \\
\hline Has fresh or cooked vegetables more than once a day (no vs. yes) & $0.83(0.80-0.87)$ & $0.83(0.78-0.89)$ & $0.83(0.78-0.89)$ \\
\hline Consumes fish regularly (at least 2-3/week) (no vs. yes) & $0.61(0.59-0.63)$ & $0.53(0.50-0.57)$ & $0.51(0.48-0.55)$ \\
\hline Eats pulses > 1/week (no vs. yes) & $0.79(0.76-0.82)$ & $0.74(0.69-0.79)$ & $0.59(0.55-0.63)$ \\
\hline Consumes nuts regularly (at least 2-3/week) (no vs. yes) & $0.76(0.74-0.79)$ & $0.73(0.68-0.78)$ & $0.70(0.66-0.75)$ \\
\hline Takes two yoghurts and/or some cheese ( $40 \mathrm{~g} /$ daily) (no vs. yes) & $0.91(0.87-0.95)$ & $0.80(0.74-0.87)$ & $0.66(0.62-0.71)$ \\
\hline
\end{tabular}

OR - odds ratio; $95 \% \mathrm{Cl}$ - confidence interval adjusted for age, body mass index, waist circumference, sleeping hours, physical activity levels, and physical fitness measurements

Table 4. Results of logistic regression models - association of participants aged 8-17 years characteristics with screen time levels

\begin{tabular}{|c|c|c|c|}
\hline Predictors & $\begin{array}{c}\text { Model } 1 \\
<2 \text { vs. } \geq 2-<3 \mathrm{~h} / \mathrm{d} \\
\text { OR }(95 \% \mathrm{Cl})\end{array}$ & $\begin{array}{c}\text { Model } 2 \\
<2 \text { vs. } \geq 3-<4 \mathrm{~h} / \mathrm{d} \\
\text { OR }(95 \% \mathrm{Cl})\end{array}$ & $\begin{array}{c}\text { Model } 3 \\
<2 \text { vs. } \geq 4 \text { h/d } \\
\text { OR }(95 \% \mathrm{Cl})\end{array}$ \\
\hline \multicolumn{4}{|l|}{ Boys } \\
\hline Age (per 1 year) & $1.12(1.11-1.13)$ & $1.17(1.16-1.18)$ & $1.20(1.19-1.21)$ \\
\hline Total obesity (normal weight vs. overweight/obese) & $1.05(1.01-1.09)$ & $1.12(1.05-1.18)$ & $1.19(1.12-1.25)$ \\
\hline Central obesity (no vs. yes) & $1.04(1.01-1.08)$ & $1.09(1.02-1.15)$ & $1.12(1.05-1.17)$ \\
\hline KIDMED index (insufficient vs. relatively/sufficient dietary habits) & $0.56(0.53-0.59)$ & $0.39(0.36-0.42)$ & $0.26(0.25-0.28)$ \\
\hline Sleeping hours (sufficient vs. insufficient) & $1.17(1.13-1.21)$ & $1.32(1.25-1.40)$ & $1.84(1.75-1.94)$ \\
\hline Physical activity levels (adequate vs. inadequate) & $1.26(1.22-1.31)$ & $1.39(1.30-1.47)$ & $1.39(1.32-1.46)$ \\
\hline Cardiorespiratory fitness (unhealthy vs. healthy) & $0.96(0.93-0.98)$ & $0.89(0.86-0.93)$ & $0.81(0.78-0.85)$ \\
\hline \multicolumn{4}{|l|}{ Girls } \\
\hline Age (per 1 year) & $1.17(1.16-1.18)$ & $1.23(1.22-1.25)$ & $1.31(1.29-1.33)$ \\
\hline Total obesity (normal weight vs. overweight/obese) & $1.04(1.00-1.08)$ & $1.05(1.01-1.09)$ & $1.07(1.00-1.14)$ \\
\hline Central obesity (no vs. yes) & $1.04(1.01-1.08)$ & $1.10(1.03-1.18)$ & $1.14(1.07-1.22)$ \\
\hline KIDMED index (insufficient vs. relatively/sufficient dietary habits) & $0.49(0.46-0.52)$ & $0.33(0.30-0.36)$ & $0.21(0.20-0.23)$ \\
\hline Sleeping hours (sufficient vs. insufficient) & $1.20(1.16-1.25)$ & $1.53(1.44-1.64)$ & $2.10(1.97-2.24)$ \\
\hline Physical activity levels (adequate vs. inadequate) & $1.16(1.12-1.20)$ & $1.30(1.22-1.39)$ & $1.31(1.23-1.40)$ \\
\hline Cardiorespiratory fitness (unhealthy vs. healthy) & $0.94(0.90-0.98)$ & $0.85(0.81-0.88)$ & $0.76(0.72-0.81)$ \\
\hline
\end{tabular}

OR - odds ratio; $95 \% \mathrm{Cl}$ - confidence interval; KIDMED - Mediterranean Diet Quality Index for children and adolescents 
tion between screen time and less healthy diet quality including lower consumption of healthy foods in children and adolescents (4). Potentially, screens cause interferes in the physiological signs of satiety and hunger, which leads to unhealthy food choices with increased consumption of low-nutrient, high-calorie foods (8).

Also, in the current study, longer screen time was associated with increased odds of total and central obesity, after adjusted for several covariates. Analytically, participants exceeding 4 $\mathrm{h} / \mathrm{d}$ on-screen time had $13 \%$ increased odds of central obesity as compared to those with $<2 \mathrm{~h} / \mathrm{d}$. A recent review reported small associations between screen time and adiposity taking into consideration cross-sectional and longitudinal studies (30). Findings from another review indicated significant positive associations between screen time and markers of adiposity, independent of dietary intake (28). Finally, a review of reviews among children and adolescents reported moderately strong evidence for associations between screen time and greater obesity (4). Probable mechanisms by which screen time may affect body weight are reduced PA and increased intake of obesogenic foods $(8,15)$.

Regarding sleep, our results suggested that the longer the screen time the increased the odds for insufficient sleep duration after adjusting for several covariates. Several review studies among children have confirmed that screen time is negatively associated with sleep outcomes such as sleep duration $(9,10,14$, 27). Taken into consideration that the above reviews use mainly observational data, causality is difficult to verify.

Moreover, our findings showed that the longer the screen time the increased the odds for insufficient PA level, independently of several potential confounders. Similar to our results, a review of Costigan et al. reported a negative association between PA and screen time, that is, that higher screen time was associated with lower PA levels (9).

Furthermore, we found that as screen time was increased, the odds of healthy CRF were decreased. Several reviews speculated that screen time for more than 2 hours per day was associated with decreased CRF $(2,4,12,28)$. Additionally, it is considered that increased screen time was associated with decreased muscular strength/endurance, and flexibility (12).

The strengths of this study include that it was conducted in a wide age range, representative group, and examined several covariates such as anthropometric and lifestyle factors.

This study had some limitations on methodological issues. For example, a possible confounding factor namely socioeconomic status that was probably connected to screen time has not been evaluated. Also, this is a cross-sectional study so causality cannot be assigned. Moreover, in the current study screen time, dietary habits, sleep, and PA were self-reported and probably it could be subject to socially desirable reporting bias. Nevertheless, schoolchildren's answers were anonymous, therefore, participants had no purpose to disassemble or misreport their responses.

\section{CONCLUSIONS}

Conclusively, the longer the screen time the unhealthier the dietary habits and lifestyle among schoolchildren. Screen time was positively associated with unhealthy dietary habits such as skipping breakfast, fast-food consumption independent of covariates. Also, the longer the screen time the increased the odds of central obesity, insufficient sleep, and inadequate PA and the decreased the odds of healthy CRF, in both genders. Future interventions should emphasize decreases in screen time, as a means of improving dietary habits and probably improving childhood obesity and lifestyle in children.

\section{Acknowledgements}

This study was supported by the Hellenic Ministry of Education and Religious Affairs, Secretariat General of Sports, OPAP S.A., Nestlé Hellas S.A., and the Department of Nutrition and Dietetics Graduate Programme, Harokopio University of Athens.

\section{Conflict of Interests}

None declared

\section{REFERENCES}

1. Domingues-Montanari S. Clinical and psychological effects of excessive screen time on children. J Paediatr Child Health. 2017;53(4):333-8.

2. Tremblay MS, Leblanc A, Janssen I, Kho M, Hicks A, Murumets K, et al. Canadian sedentary behaviour guidelines for children and youth. Appl Physiol Nutr Metab. 2011;36(1):59-64.

3. Royal College of Paediatrics and Child Health. The health impacts of screen time: a guide for clinicians and parents [Internet]. RCPCH [cited 2019 Oct 30]. Available from: https://www.rcpch.ac.uk/sites/default/ files/2018-12/rcpch_screen_time_guide_-_final.pdf.

4. Stiglic N, Viner RM. Effects of screen time on the health and well-being of children and adolescents: a systematic review of reviews. BMJ Open. 2019;9(1):e023191. doi: 10.1136/bmjopen-2018-023191.

5. Hare-Bruun H, Nielsen BM, Kristensen PL, Møller NC, Togo P, Heitmann BL. Television viewing, food preferences, and food habits among children: a prospective epidemiological study. BMC Public Health. 2011;11:311. doi: 10.1186/1471-2458-11-311.

6. American Academy of Pediatrics, Committee on Public Education Children, adolescents, and television. Pediatrics. 2001;107(2):423-6.

7. Colley RC, Wong SL, Garriguet D, Janssen I, Connor Gorber S, Tremblay MS. Physical activity, sedentary behaviour and sleep in Canadian children: parent-report versus direct measures and relative associations with health risk. Health Rep. 2012;23(2):45-52.

8. Craigie AM, Lake AA, Kelly SA, Adamson AJ, Mathers JC. Tracking of obesity-related behaviours from childhood to adulthood: A systematic review. Maturitas. 2011;70(3):266-84.

9. Costigan SA, Barnett L, Plotnikoff RC, Lubans DR. The health indicators associated with screen-based sedentary behavior among adolescent girls: a systematic review. J Adolesc Health. 2013;52(4):382-92.

10. Duch H, Fisher EM, Ensari I, Harrington A. Screen time use in children under 3 years old: a systematic review of correlates. Int J Behav Nutr Phys Act. 2013;10:102. doi: 10.1186/1479-5868-10-102.

11. Busch V, Manders LA, de Leeuw JR. Screen time associated with health behaviors and outcomes in adolescents. Am J Health Behav. 2013;37(6):819-30.

12. Carson V, Hunter S, Kuzik N, Gray CE, Poitras VJ, Chaput J, et al. Systematic review of sedentary behaviour and health indicators in schoolaged children and youth: an update. Appl Physiol Nutr Metab. 2016;41(6 Suppl 3):S240-65.

13. van Ekris E, Altenburg TM, Singh AS, Proper KI, Heymans MW, Chinapaw MJ. An evidence-update on the prospective relationship between childhood sedentary behaviour and biomedical health indicators: a systematic review and meta-analysis. Obes Rev. 2016;17(9):833-49.

14. Tremblay MS, LeBlanc AG, Kho ME, Saunders TJ, Larouche R, Colley $\mathrm{RC}$, et al. Systematic review of sedentary behaviour and health indicators in school-aged children and youth. Int J Behav Nutr Phys Act. 2011;8:98. doi: 10.1186/1479-5868-8-98.

15. Shqair AQ, Pauli LA, Costa VPP, Cenci M, Goettems ML. Screen time, dietary patterns and intake of potentially cariogenic food in children: a systematic review. J Dent 2019;86:17-26.

16. Ghavamzadeh S, Khalkhali HR, Alizadeh M. TV viewing, independent of physical activity and obesogenic foods, increases overweight and obesity in adolescents. J Health Popul Nutr. 2013;31(3):334-42. 
17. Bickham DS, Blood EA, Walls CE, Shrier LA, Rich M. Characteristics of screen media use associated with higher BMI in young adolescents. Pediatrics. 2013;131(5):935-41.

18. Cole T, Bellizzi M, Flegal K, Dietz WH. Establishing a standard definition for child overweight and obesity worldwide: international survey. BMJ. 2000;320:1240. doi: 10.1136/bmj.320.7244.1240.

19. Browning LM, Hsieh SD, Ashwell M. A systematic review of waist-toheight ratio as a screening tool for the prediction of cardiovascular disease and diabetes: 0.5 could be a suitable global boundary value. Nutr Res Rev. 2010;23(2):247-69.

20. Council of Europe; Committee for the Development of Sport. Eurofit: handbook for the Eurofit tests of physical fitness. 2nd ed. Strasbourg: Council of Europe; 1993.

21. Ruiz JR, Cavero-Redondo I, Ortega FB, Welk GJ, Andersen LB, MartinezVizcaino V. Cardiorespiratory fitness cut points to avoid cardiovascular disease risk in children and adolescents; what level of fitness should raise a red flag? A systematic review and meta-analysis. Br J Sports Med. 2016;50(23):1451-8.

22. Centers for Disease Control and Prevention. Youth Risk Behavior Surveillance System (YRBSS) [Internet]. CDC [cited 2019 Nov 10]. Available from: http://www.cdc.gov/HealthyYouth/yrbs/.

23. Piercy KL, Troiano RP, Ballard RM, Carlson SA, Fulton JE, Galuska DA, et al. The Physical Activity Guidelines for Americans. JAMA. 2018;320(19):2020-8.

24. Paruthi S, Brooks LJ, D'Ambrosio C, Hall WA, Kotagal S, Lloyd RM, et al. Consensus statement of the American Academy of Sleep Medicine on the recommended amount of sleep for healthy children: methodology and discussion. J Clin Sleep Med. 2016;12(11):1549-61.
25. Serra-Majem L, Ribas L, Ngo J, Ortega RM, Garcia A, Perez-Rodrigo C, et al. Food, youth and the Mediterranean diet in Spain. Development of KIDMED, Mediterranean Diet Quality Index in children and adolescents. Public Health Nutr. 2004;7(7):931-5.

26. Marshall SJ, Gorely T, Biddle SJ. A descriptive epidemiology of screen-based media use in youth: a review and critique. J Adolesc. 2006;29(3):333-49.

27. Hale L, Guan S. Screen time and sleep among school-aged children and adolescents: a systematic literature review. Sleep Med Rev. 2015;21:50-8.

28. Fletcher E, Leech R, McNaughton SA, Dunstan DW, Lacy KE, Salmon $\mathrm{J}$. Is the relationship between sedentary behaviour and cardiometabolic health in adolescents independent of dietary intake? A systematic review. Obes Rev. 2015;16(9):795-805.

29. Borghese MM, Tremblay MS, Leduc G, Boyer C, Bélanger P, LeBlanc $\mathrm{AG}$, et al. Independent and combined associations of total sedentary time and television viewing time with food intake patterns of 9- to 11-year-old Canadian children. Appl Physiol Nutr Metab. 2014;39(8):937-43.

30. Biddle SJ, García Bengoechea E, Wiesner G. Sedentary behaviour and adiposity in youth: a systematic review of reviews and analysis of causality. Int J Behav Nutr Phys Act. 2017;14(1):43. doi: 10.1186/s12966-017$0497-8$.

Received January 5, 2020 Accepted in revised form October 22, 2020 